\title{
Narcolepsy: current treatment options and future approaches
}

\author{
Michel Billiard \\ Department of Neurology, Gui de \\ Chauliac Hospital, Montpellier, France
}

\begin{abstract}
The management of narcolepsy is presently at a turning point. Three main avenues are considered in this review: 1) Two tendencies characterize the conventional treatment of narcolepsy. Modafinil has replaced methylphenidate and amphetamine as the first-line treatment of excessive daytime sleepiness (EDS) and sleep attacks, based on randomized, double blind, placebo-controlled clinical trials of modafinil, but on no direct comparison of modafinil versus traditional stimulants. For cataplexy, sleep paralysis, and hypnagogic hallucinations, new antidepressants tend to replace tricyclic antidepressants and selective serotonin reuptake inhibitors (SSRIs) in spite of a lack of randomized, double blind, placebo-controlled clinical trials of these compounds; 2) The conventional treatment of narcolepsy is now challenged by sodium oxybate, the sodium salt of gammahydroxybutyrate, based on a series of randomized, double-blind, placebo-controlled clinical trials and a long-term open label study. This treatment has a fairly good efficacy and is active on all symptoms of narcolepsy. Careful titration up to an adequate level is essential both to obtain positive results and avoid adverse effects; 3 ) A series of new treatments are currently being tested, either in animal models or in humans, They include novel stimulant and anticataplectic drugs, endocrine therapy, and, more attractively, totally new approaches based on the present state of knowledge of the pathophysiology of narcolepsy with cataplexy, hypocretine-based therapies, and immunotherapy.
\end{abstract}

Keywords: narcolepsy, treatment, conventional drugs, modafinil, sodium oxybate, future treatments

\section{Introduction}

Narcolepsy is a disabling condition characterized by three groups of symptoms: excessive daytime sleepiness (EDS) and irresistible sleep episodes, plus or minus automatic behaviors; cataplexy, a sudden loss of muscle tone triggered by strong emotions such as laughter or humorous experiences, and other abnormal rapid eye movement (REM) sleep manifestations, sleep paralysis and hypnagogic hallucinations; disturbed nocturnal sleep, and parasomnias. The cardinal symptoms are excessive daytime sleepiness/sleep attacks and cataplexy. The diagnosis of narcolepsy rests on clinical grounds. However, polysomnography followed by a multiple sleep latency test (MSLT) is greatly recommended to document a mean sleep latency $\leq 8 \mathrm{~min}$ and two or more sleep onset REM periods (American Academy of Sleep Medicine 2005).

Recently the second edition of the International Classification of Sleep Disorders (ICSD-2) has recognized three forms of narcolepsy: narcolepsy with cataplexy, narcolepsy without cataplexy, and narcolepsy due to medical condition (American Academy of Sleep Medicine 2005).

The prevalence of narcolepsy with cataplexy is estimated to be $0.02 \%-0.05 \%$ (Hublin et al 1994a; Ohayon et al 2002; Silber et al 2002; Wing et al 2002). Limited data suggest that the incidence is 0.74 per 100,000 person-years (Silber et al 2002)). Narcolepsy without cataplexy is thought to represent between $10 \%$ and $50 \%$ of all 
narcolepsy cases, but the precise prevalence is unknown. Narcolepsy due to medical condition is exceptional, with 115 cases published in the world literature (Nishino and Kanbayashi 2005).

The age of onset varies from early childhood to 50, with a bimodal distribution, including a main peak around the age of 15 and a secondary peak around the age of 36 (Dauvilliers et al 2001).

The general course of narcolepsy is hard to systematize. The pattern tends to be for EDS and irresistible sleep attacks to persist throughout life, even if improvements are commonly observed after retirement, probably in part due to a better schedule of sleep and activity. Cataplexy may vanish spontaneously in some patients. Hypnagogic hallucinations and sleep paralysis are most often transient. Poor sleep does not tend to improve. Narcolepsy has a negative impact on several aspects of life such as driving ability, professional performance, familial equilibrium, and mood (Broughton et al 1981). One particular complication is status cataplecticus characterized by cataplexy lasting hours and days and confining the patient to bed. Status cataplecticus occurs either spontaneously or, more often, after suspending treatment for cataplexy because of adverse effects.

The etiology of narcolepsy is not yet fully clarified. However, it is clear that mutations in the hypocretin (orexin) receptor 2 gene cause genetic narcolepsy in several animal species (Chemelli et al 1999; Lin et al 1999) and there is no doubt that hypocretin/orexin deficiency is the most frequent cause of narcolepsy with cataplexy in humans (Peyron et al 2000; Thannickal et al 2000).

The management of narcolepsy has evolved over the past few years and will likely evolve more dramatically in the coming years. Treatment guidelines have been published (Standards of Practice Committee of the American Sleep Disorders Association 1994; Standards of Practice Committee 2001; Britton et al 2002; Billiard et al 2006; Keam et al 2007; Morgenthaler et al 2007).

The treatment of excessive daytime sleepiness and sleep attacks, traditionally based on amphetamines and amphetamine-like drugs, is now replaced by modafinil. New antidepressants have replaced tricyclics and selective serotonin reuptake inhibitors (SSRIs) in the treatment of cataplexy and other abnormal REM sleep manifestations.

Gamma-hydroxybutyrate, a treatment first used in the 1980 s, has recently re-emerged under the name sodium oxybate, as a treatment of all symptoms of narcolepsy.

New approaches including symptomatic neurotransmitters and endocrine therapy, hypocretine-based therapies, immune-based therapies, and skin warming or cooling are currently being developed.

\section{The conventional treatments of narcolepsy Treatment of excessive daytime sleepiness and sleep attacks \\ Amphetamines}

Amphetamines, including d,l-amphetamine, d-amphetamine (sulfate) and met-amphetamine (chlorhydrate) have been used for narcolepsy since the 1930s (Prinzmetal and Bloomberg 1935). At low dose, their main effect is to release dopamineand to a lesser extent noradrenaline - through reverse efflux via monoaminergic transporters, the dopamine transporter (DAT) and the norepinephrine transporter (NET). DAT and NET move dopamine and norepinephrine, respectively, from the outside to the inside of the cell. This process is sodium dependent. At higher doses, amphetamine interacts with the vascular monoamine transporter 2 (VMAT2). The vesicularization of the monoamines (dopamine, norepinephrine, serotonine, and histamine) in the central nervous system depends on VMAT2). At a dose of 10-60 mg/day, amphetamines are very effective. However, they may be responsible for a number of adverse effects, irritability, headache, nervousness, palpitations, insomnia, and less often orofacial dyskinesia, anorexia, nausea, excessive sweating, and psychosis. Tolerance to amphetamine effect may develop in up to one third of patients (Mitler et al 1994), addiction is generally not a problem in narcoleptic patients (Guilleminault 1993).

\section{Methylphenidate}

Methylphenidate, a N-methyl derivative of amphetamine, also induces dopamine release, but does not have a major effect on monoamine storage. In comparison with amphetamines, methylphenidate has a much shorter elimination half-life (2-7 hours) (Parkes and Dahlitz 1993). The daily dose is 10-60 mg a day. Adverse effects are the same as with amphetamines, but milder. Tolerance may develop but abuse potential is low. A sustained release form is available and can be useful in some cases.

\section{Modafinil}

Modafinil has been available in France for more than 20 years under controlled hospital-based prescription. The drug was approved in France in 1994 and in the US in late 1998.

Compared with amphetamine, modafinil has an additional phenyl (sulfinyl group) and an amide instead of an amine group, which suggests a distinct mechanism of action. 
However, the mode of action is still unclear even if a dopamine reuptake inhibition is very likely involved (Mignot et al 1994; Nishino et al 1998; Wisor et al 2001). The elimination half-life is 13.8 hours and the maximum concentration is achieved in 2-4 hours.

Unlike previous drugs modafinil has benefited from randomized, double-blind, placebo-controlled trials, which have shown the drug to be significantly effective on excessive daytime sleepiness at a dose of $300 \mathrm{mg}$ (Billiard et al 1994), or at doses of 200 and $400 \mathrm{mg}$ (Broughton et al 1997; US Modafinil in Narcolepsy Multicenter Group 1998, 2000; Beuersterien et al 1999; Moldofsky et al 2000).

The starting dose is 100-200 $\mathrm{mg}$ and the usual dose between 100 and $400 \mathrm{mg}$, given either as a single morning dose or as a split dose. The most common adverse effects are limited. They include headache, nausea, nervousness, and rhinitis, especially at the onset of treatment. There is no evidence of tolerance (Thorpy et al 2004).

The possibility of induction of human hepatic cytochrome P450 enzymes exists, hence an increase of the metabolism of oral contraceptives. Accordingly, the usual recommendation is for the patient to use another form of contraception while taking modafinil and for one month after stopping the medication.

Today modafinil is the most widely precribed drug for excessive daytime sleepiness. It is effective or very effective in $60 \%$ of patients and partially effective in $20 \%$ (Billiard et al 2007). In case of insufficient efficacy or of fading out of the activity, modafinil may be supplemented by either methylphenidate (regular short-acting formulation) on an as-needed basis or at times when sleepiness is most severe, or by sodium oxybate (Black and Houghton 2006)

\section{Mazindol}

Mazindol is an imidazole derivative with similar pharmacological effects to the amphetamines. It is a weak releasing agent for dopamine, but it also blocks dopamine and norepinephrine reuptake with high affinity. Its elimination half-life is around 10 hours. The usual dosage is $2-6 \mathrm{mg} /$ day. Mazindol reduces excessive daytime sleepiness in 53\%-60\% of patients (Shindler et al 1985). Adverse effects include dry mouth, gastro-intestinal upset, anorexia, headache, and sweating. Mazindol has been withdrawn from the market in several countries due to reports of valvular abnormalities.

\section{Selegiline}

Selegiline is a potent irreversible MAO type-B inhibitor. It is metabolically converted to desmethyl selegiline, 1-amphetamine and 1-methamphetamine. The regular dose is $10-40 \mathrm{mg} / \mathrm{day}$. It has been shown to significantly reduce excessive daytime sleepiness at a dose of at least $20 \mathrm{mg}$ (Mayer et al 1995). The main adverse effects are sympathomimetic and interaction with other drugs (Hublin et al 1994b; Mayer et al 1995). A diet low in tyramine is recommended with higher dosages of selegiline to avoid the risk of hypertensive reactions.

\section{Pemoline}

Pemoline is an oxazolidine derivative with a long half-life (12 hours), which selectively blocks dopamine reuptake and only weakly stimulates dopamine release. This drug is usually better tolerated than amphetamine in terms of adverse effects (Mitler et al 1986). However, due to its potential fatal hepato-toxicity, it has been withdrawn from the market in most countries.

\section{Behavioral treatment}

In addition to pharmacological treatment, behavioral treatment measures are always advisable. Essentially, the studies available (Rogers et al 2001; Broughton et al 2007) support the recommendation to take planned naps during the day, as naps decrease sleep tendency and shorten reaction time. Because of limitations on work or home times, naps are best scheduled on a patient-by-patient basis.

\section{Treatment of cataplexy and other REM sleep manifestations, sleep paralysis, and hypnagogic hallucinations}

Tricyclic antidepressants

Cataplexy was primarily treated using a tricyclic antidepressant, imipramine (Akimoto et al 1960). Tricyclic antidepressants are monoamine reuptake inhibitors but lack specificity for any single monoamine, both with respect to their parent compounds and because of the existence of active metabolites (Tatsumi et al 1997). Possible mechanisms of action include anticholinergic effects, serotonergic reuptake inhibition, or adrenergic reuptake inhibition. Tricyclic antidepressants are active on cataplexy at doses below usual antidepressant dose range efficacy. Clomipramine (in Europe and Japan) and protriptyline (in the US) have been the most widely used. Clomipramine is principally a serotonergic reuptake inhibitor, but metabolizes into desmethylimipramine, a metabolite with adrenergic effects. Active doses are typically 25-75 mg daily. However, low doses of 10-20 mg daily are often effective, and it is always advisable to start with them to avoid anticholinergic effects. Protriptyline is mostly a 
norepinephrine uptake inhibitor. Active doses are 2.5-10 mg daily. As for clomipramine, it is always advisable to start with low doses.

Adverse effects consist of anticholinergic effects including dry mouth, sweating, constipation, tachycardia, weight gain, hypotension, difficulty in urinating, and impotence. In the case of abrupt withdrawal, a marked increase in number and severity of cataplectic attacks, a situation referred to as rebound cataplexy, or even status cataplecticus may occur (Martinez-Rodriguez et al 2002).

\section{Monoamine oxidase (MAO) type-A inhibitors}

MAO type-A inhibitors increase the activity of endogenous catecholamines by inhibiting monoamine oxidase. Although these drugs, specially phenelzine, have been used with success in small series (Wyatt et al 1971), they lack controlled clinical trials. Moreover these drugs have adverse effects including orthostatic hypotension, edema, weight gain, and impotence. Above all the ingestion of tyramine-rich foods, such as cheese and wine, may result in hypertensive crisis. Thus these drugs are not in use any more.

\section{Selective serotonin-reuptake inhibitors (SSRIs)}

These compounds are much more selective than tricyclic antidepressants toward the serotonergic transporter, although most of them have affinities for other monoamine transporters at 10-100 times higher concentrations (Schachter et al 1980; Langdon et al 1986). In comparison with tricyclics, higher doses are required and effects less pronounced (Nishino and Mignot 1997). The daily dosage varies with the product. As a group, SSRIs possess the following adverse effects: headache, nausea, weight gain, dry mouth, erectile and ejaculation dysfunction, and decreasef libido. Adverse effects are less pronounced than with tricyclic antidepressants. However, a flattened affect or sexual difficulty may be encountered.

\section{Newer antidepressants}

Despite the lack of randomized, double-blind, placebo controlled studies, some products are increasingly used.

\section{Noradrenergic uptake inhibitors}

Viloxazine at a dose of 100-300 mg per day (Guilleminault et al 1986), reboxetine at a dose of 2-10 $\mathrm{mg}$ (Larrosa et al 2001) and atomoxetine at a dose of 40-60 mg per day (Niederhofer 2005) are generally active against cataplexy. Note that the first two compounds are available only in a few European countries. Adverse effects are limited with the exception of rash, nausea with viloxazine, minimal sedation, and cardiovascular liabilities with reboxetine, and tachycardia, hypotension, and the rare but potential liver toxicity with atomoxetine

Noradrenaline and serotonin-reuptake inhibitors

Venlafaxine is increasingly used at a dose of 37.5-300 mg daily. The main adverse effects are gastrointestinal upset and less frequently asthma and hypertension (Smith et al 1996). Status cataplecticus has been reported with a shift from immediate release venlafaxine to the extended release formulation (Plazzi et al 2007).

\section{Mazindol and selegiline}

Each of these drugs has combined anticataplectic effects and stimulant properties (Shindler et al 1985; Iijima et al 1986; Roselaar et al 1987). No comparative study with other anticataplectic drugs is available.

\section{Behavioral treatment}

In contrast with excessive daytime sleepiness, there is no established behavioral treatment of cataplexy, except for avoiding situations that trigger cataplexy.

\section{Treatment of disturbed nocturnal sleep}

The standard treatment is based on hypnotics, benzodiazepines and non-benzodiazepines, which may delay the first awakening of the night. However, a single study (Thorpy et al 1992) has shown an improvement of sleep efficiency and overall sleep quality with triazolam $0.25 \mathrm{mg}$ given for two nights only, and no study has been performed with either zopiclone (now referred to as ezopiclone in the US) or zolpidem or zaleplon.

\section{Sodium oxybate, a new approach to the treatment of narcolepsy}

Gamma-hydroxybutyrate (GHB) is a natural metabolite of gamma-aminobutyrate that may act as a neurotransmitter via its own receptors and via the stimulation of GABA-B receptors (Maitre 1997; Pardi and Black 2006).

Broughton and Mamelak (1979) were the first to support that GHB was useful to control cataplexy, enhance daytime alertness and improve night sleep in narcoleptic patients, and for years GHB was used at a dose of $2.5 \mathrm{~g}$ at bedtime and $1.25 \mathrm{~g}$ later in the night, with inconstant results. Moreover, due to its misuse in athletes for its metabolic effects and its use as a date rape because of its rapid sedative effects, the use of GHB became extremely restricted.

However, based on the early clinical results, GHB has re-emerged in the past few years under the name sodium 
oxybate, the sodium salt of GHB, which is used for the exogenous administration of GHB. Sodium oxybate has been tested in a number of randomized, double blind, placebocontrolled trials. Main results have been a dose-dependent (3 or 4.5-9 g nightly) reduction of EDS and sleep attacks, significant at the 6 or $9 \mathrm{~g}$ doses (US Xyrem ${ }^{\circledR}$ Multicenter Study Group 2002; Xyrem ${ }^{\circledR}$ International Study Group 2005); a dose-dependent ( 3 or 4.5-9 g nightly) reduction of the number of cataplectic attacks significant at the $9 \mathrm{~g}$ dose (US Xyrem ${ }^{\circledR}$ Multicenter Study Group 2002, 2004; Xyrem ${ }^{\circledR}$ International Study group 2005); and a reduction of nighttime awakenings at the $6 \mathrm{~g}$ dose, becoming significant at the $9 \mathrm{~g}$ dose (US Xyrem ${ }^{\circledR}$ Multicenter Study Group 2002). Moreover a long-term (12 months) open label study showed diminished EDS, significant at 4 weeks, maximal after 8 weeks; a significant diminution of cataplectic attacks; and night-time awakenings less frequent, although not signicantly (US Xyrem ${ }^{\circledR}$ Multicenter Study Group 2003). Finally a recent randomized, double blind, placebo-controlled trial showed that modafinil and sodium oxybate were both effective on EDS, with an additive effect (Black and Houghton 2006).

Sodium oxybate is given at a starting dose of $4.5 \mathrm{~g} / \mathrm{night}$ divided into two equal doses of $2.25 \mathrm{~g} /$ night. The dose may be increased to a maximum dosage of $9 \mathrm{~g} / \mathrm{night}$, divided into two equal doses of $4.5 \mathrm{~g} /$ night, by increments of $1.5 \mathrm{~g}$ at 2-week intervals. Most patients will start to feel better within the first few days, but optimal response at any given dose may take as long as 8-12 weeks.

The most problematic adverse effect was expected to be drug abuse. However, the monitored prescription program in the US revealed that this is a very low risk in narcoleptic patients. In the various clinical trials of the product (US Xyrem ${ }^{\circledR}$ Multicenter Study Group 2002; Xyrem ${ }^{\circledR}$ International Study Group 2005) adverse events with $>5 \%$ incidence included nausea, vomiting, dizziness, and enuresis. Today, with the clinical experience accumulated over the world, nausea appears as the main adverse effect, although it can be treated effectively with anti-emetic drugs. Enuresis is relatively rare. On the other hand psychiatric effects such as depression or suicidal ideation are to be considered and it is advisable not to prescribe sodium oxybate to depressed hypersomniac patients

\section{Recommendations (Table I) Excessive daytime sleepiness and sleep attacks}

A conservative therapy, based on the well tested efficay of the drug and its limited adverse effects, consists of using
Table I Recommendations for the treatment of narcolepsy. A. Excessive daytime sleepiness/sleep attacks. B. Cataplexy, sleep paralysis, and hypnagogic hallucinations. C. Disturbed nocturnal sleep

\begin{tabular}{|c|c|c|}
\hline & Conservative therapy & - More recent therapy \\
\hline & $\begin{array}{l}\text { Modafinil } 100-400 \mathrm{mg} / \mathrm{day} \\
\text { in a split dose, } \\
\text { possibly supplemented with } \\
\text { either } \\
\text { methylphenidate or sodium } \\
\text { oxybate } \\
\text { Dexamphetamine in case of } \\
\text { severe and Intractable EDS }\end{array}$ & $\begin{array}{l}\text { Sodium oxybate at a starting dose of } \\
4.5 \mathrm{~g} / \text { night, divided into } 2 \text { equal } \\
\text { doses of } 2.25 \mathrm{~g} \text {, incremented by } 1.5 \mathrm{~g} \\
\text { at a } 2 \text {-week interval, up to a } \\
\text { maximum of } 9 \mathrm{~g} \text {, possibly } \\
\text { supplemented with modafinil }\end{array}$ \\
\hline B & Conservative therapy & - More recent therapy \\
\hline & $\begin{array}{l}\text { - first line } \\
\text { Venlafaxine } 37.5-300 \\
\mathrm{mg} / \text { day or } \\
\text { Atomoxetine } 40-60 \\
\mathrm{mg} / \text { day } \\
\text { - second line } \\
\text { Clomipramine } 10-60 \\
\mathrm{mg} / \text { day or SSRI }\end{array}$ & $\begin{array}{l}\text { Sodium oxybate at a starting dose } \\
\text { of } 4.5 \text { equal doses of } 2.25 \mathrm{~g} \text {, } \\
\text { incremented by } 1.5 \mathrm{~g} \text { at a } 2 \text {-week } \\
\text { interval, up to a maximum of } 9 \mathrm{~g}\end{array}$ \\
\hline & Conservative therapy & - More recent therapy \\
\hline & $\begin{array}{l}\text { Benzodiazepine or } \\
\text { nonbenzodiazepine } \\
\text { hypnotic: one tablet at } \\
\text { bedtime }\end{array}$ & $\begin{array}{l}\text { Sodium oxybate at a } \\
\text { starting dose of } 4.5 \mathrm{~g} / \mathrm{night} \text { divided } \\
\text { into } 2 \text { equal doses of } 2.25 \mathrm{~g} \text {, } \\
\text { incremented by } 1.5 \mathrm{~g} \text { at a } 2 \text {-week } \\
\text { interval, up to a maximum of } 9 \mathrm{~g}\end{array}$ \\
\hline
\end{tabular}

modafinil, in a split dose strategy, either with $200 \mathrm{mg}$ at 7:00 and 12:00 or $400 \mathrm{mg}$ in the morning and $200 \mathrm{mg}$ at noon (Schwartz et al 2004), as the first-line treatment. In case of insufficient efficacy or of secondary relapse, modafinil is supplemented with either methylphenidate (on an as-needed basis) or sodium oxybate at a dose of $4.5 \mathrm{~g}$ in two divided doses at night. Finally severe and intractable excessive daytime sleepiness may require the use of amphetamine.

A more recent therapeutic attitude consists in using sodium oxybate as a first line treatment based on an average better response of patients to sodium-oxybate and on some results of Black and Houghton's study (2006) (significant reduction of ESS scores at the end of the trial in the sodium-oxybate and in the sodium-oxybate/modafinil groups, not in the modafinil group, and fewer weekly sleep attacks at the end of the trial in the sodium oxybate and in the sodium oxybate/modafinil groups, not in the modafinil group). Supplementation with modafinil is indicated in case of insufficient efficacy (Black and Houghton 2006). Having to take a second dose during the night is not a problem for a large majority of patients and some content themselves with 
one dose when they do not wake up during the night. Patients must refrain from alcohol; if they have absorbed alcohol at dinner they should not take the first dose of the night.

In either case the place for other stimulants, seligiline or mazindol, has become extremely limited

\section{Cataplexy and other REM sleep manifestations}

The conservative attitude is to use new antidepressants, specially venlafaxine or atomoxetine, based on their recognized efficacy and the absence of major adverse effects, in spite of their lack of randomized, double-blind, placebo controlled clinical trials, while the more recent therapeutic approach, based on multiple randomized, double-blind, placebo-controlled clinical trials, is to use directly sodium oxybate and titrate the dose up to an adequate level, to obtain positive results and avoid adverse effects, as indicated for the treatment of excessive daytime sleepiness and sleep attacks.

Should these treatments be inefficient tricyclic antidepressants or SSRIs can be tried.

\section{Disturbed nocturnal sleep}

The conservative approach is to use benzodiazepines or non benzodiazepines. However, the best current treatment is sodium oxybate in two nightly doses.

\section{Approval by agencies (Table 2)}

Reflecting the limited number of medications which have been tested through randomized, double blind, placebo controlled, clinical trials, only a few medications, mainly modafinil, methyphenidate and sodium oxybate have been approved by the official agencies, European Medicines Agency (EMEA), US Food and Drug Administration (US FDA), and national agencies .

\section{Special issues}

\section{Associated conditions}

Obstructive sleep apnea syndrome (OSAS) (Chokroverty 1986; Kales et al 1987; Mayer et al 2002), periodic limb movements in sleep (PLMS) (Montplaisir et al 2000; Mayer et al 2002), and depression (Merrit et al 1992; Mayer et al 2002) are more prevalent in narcoleptic patients than in the general population. OSAS aggravates EDS. It should be treated no differently to the general population. There is no documented effect of PLMS on excessive daytime sleepines in narcoleptic patients and there is usually no indication to treat them. As for depression, antidepressant drugs and
Table 2 Approval of the various medications by European and US agencies. A. Medications for EDS and sleep attacks (B, Belgium, DK, Denmark, F, France, D, Germany, CH, Switzerland). B. Medications for cataplexy (I, Italy, SP, Spain, S, Sweden, CH Switzerland, UK, United Kingdom, B, Belgium, DK, Denmark, F, France, D, Germany) (RIs, reuptake inhibitors). C. Medications for disturbed nocturnal sleep of narcolepsy with cataplexy patients

\begin{tabular}{|c|c|c|}
\hline \multicolumn{3}{|l|}{$\mathbf{A}$} \\
\hline Medications & EMEA & US FDA \\
\hline Modafinil & approved & approved \\
\hline Sodium oxybate & approved & approved \\
\hline Methylphenidate & approved in B, DK, F, D, CH & approved \\
\hline Dexamphetamine & not approved & approved \\
\hline Methamphetmine & not approved & not approved \\
\hline Mazindol & not approved & not approved \\
\hline Selegiline & not approved & not approved \\
\hline \multicolumn{3}{|l|}{ B } \\
\hline Medications & EMEA & US FDA \\
\hline Sodium oxybate & approved & approved \\
\hline Clomipramine & approved in I, SP, S, CH, UK & not approved \\
\hline Protriptyline & not approved & not approved \\
\hline SSRIs & approved in B, DK, F, D, CH & not approved \\
\hline Noradrenaline RIs & not approved & not approved \\
\hline Nor./serotonin Rls & not approved & not approved \\
\hline Mazindol & not approved & not approved \\
\hline Selegiline & not approved & not approved \\
\hline \multicolumn{3}{|l|}{ C } \\
\hline Medications & EMEA & US FDA \\
\hline $\begin{array}{l}\text { Benzodiazepines or } \\
\text { nonbenzodiazepines }\end{array}$ & not approved & not approved \\
\hline Sodium oxybate & not approved & not approved \\
\hline
\end{tabular}

psychotherapy are indicated. However, there is no systematic study of these treatments in narcoleptic patients.

\section{REM sleep behavior disorder (RBD)}

There is a high incidence of RBD in narcoleptic patients (Schenck and Mahowald 1992; Nightingale et al 2005; Marelli et al 2006). Tricyclic antidepressants and the SSRIs may trigger or exacerbate RBD. Despite the lack of a specific therapeutic trial in narcoleptic patients, clonazepam is recommended. According to Boeve et al (2003), melatonin at a dose of $3-13 \mathrm{mg} /$ night would be successful in $57 \%$ of cases.

\section{Child narcolepsy}

There is no consistent, randomized, placebo-controlled, clinical trial available in narcoleptic patients younger than 18 years. However, children deserve to be treated as well, and it is even vital to treat the condition as early as possible, in order to avoid the occurrence of school difficulties. Thus the same drugs as for adults are used, 
on the condition of initially prescribing at the weakest possible dose. Interestingly, two off-label studies have been conducted in children. A first study has assessed the effects of modafinil on excessive daytime sleepiness, mood, and academic performance in 13 children with narcolepsy or idiopathic hypersomnia. Subjective (as reported by parents) and objective assessments were performed. For approximately $90 \%$ of the children tested, parents reported a favorable response with the reduction in sudden sleep attacks. Seven children underwent repeated nocturnal polysomnography and multiple sleep latency test (MSLT), a test measuring sleep latency five times a day to evaluate the degree of sleepiness, and the mean sleep latency was significantly prolonged (Ivanenko et al 2003). In a second study assessing the effects of sodium oxybate in 8 children with narcolepsy with cataplexy, 7/8 improved. Cataplexy frequency decreased and the score on the Epworth Sleepiness Scale, a behavioral assessment of sleepiness, improved (Murali et al 2006).

\section{Pregnancy}

In general, due to insufficient clinical studies, stimulant and anti-cataplectic drugs are not recommended during pregnancy. Thus, it is advisable to progressively withdraw pregnant women from their medication(s). The withdrawal must be slow to avoid a marked cataplexy rebound that usually occurs on day 3 or 4 .

\section{Status cataplecticus}

Abrupt withdrawal of those antidepressants which decrease REM sleep, specially tricyclic antidepressants and SSRIs, may induce a significant rebound of cataplexy, or even a status cataplecticus. This symptom is generally difficult to treat, thus the need for slow discontinuation of the antidepressant when required. The recommended withdrawal schedule is one dose every 4 days.

\section{Good practice points}

Once diagnosed, patients must be given as much information as possible about their condition (nature of the disorder, genetic implication, medications available) and their potential adverse effects to help them cope with a potentially debilitating condition.

Regular follow-up is essential to monitor response to treatment, adapt the treatment in case of insufficient response to treatment or adverse effects, and above all encourage the patient to stand on therapy, as stimulants provide, at best, moderate improvement in alertness rather than full restoration. Another polysomnographic evaluation of patients should be considered in case of worsening of symptoms.

\section{Future treatments}

Current treatments for human narcolepsy are symptomatically based. However, given the major developments in understanding the neurobiological basis of the condition, new therapies are likely to emerge. There are currently several focuses for future treatment

\section{Symptomatic neurotransmitters}

Novel compounds in development include stimulants and anti-cataplectic drugs.

1. Armodafinil is the r-enantiomer of the racemic compound, modafinil. Modafinil contains equal amounts of both the r-enantiomer and the s-enantiomer. The r-enantiomer has a half-life of 10-14 hours versus 3-4 hours for the s-enantiomer. In addition, elimination of the s-enantiomer is three times faster than elimination of the r-enantiomer. In association with the longer half-life of armodafinil, plasma concentrations in humans have been found to be higher during wakefulness later in the day when compared with racemic modafinil. Armodafinil was evaluated through a multicenter, randomized, doubleblind, placebo-controlled trial including 196 patients with narcolepsy (Harsh et al 2006). Armodafinil significantly improved ability to sustain wakefulness throughout the day in patients with narcolepsy. It also significantly improved overall clinical condition, memory, attention, and fatigue compared with placebo.

2. For antidepressant therapies novel dual (duloxetine, milnacipram) (Kent 2000) and triple (dopamine, serotonin, and adrenergic, eg, DOV 216,303) (Beer et al 2004) monoaminergic reuptake inhibitors are being tested.

3. The importance of histamine in sleep regulation has long been suspected considering the sedative effects of the $\mathrm{H} 1$ receptor antagonist. Thus the use of $\mathrm{H} 1$ receptor antagonists was a logical possibility of treatment. Unfortunately there is a lack of available CNS-penetrating compounds. However, it was shown, as early as 1990, that oral administration of alpha-methylhistamine, a H3 receptor agonist, significantly increased deep slow wave sleep, while that of thiopiramide, a $\mathrm{H} 3$ receptor antagonist, enhanced wakefulness in a marked and dose-dependent manner (Lin et al 1990). According to the same author (Lin 2000) H3-receptor antagonists, through desinhibition of $\mathrm{H} 3$-autoreceptors, would enhance synaptic histamine that in turn would activate post-synaptic H1-receptors, promoting 
wakefulness. In this context it is of special importance that H3-receptor antagonists and H3-receptor inverse agonists have been shown to be effective on sleepiness and cataplexy in narcoleptic canines (Tedford et al 1999) and that thiopiramide, a H3-receptor antagonist, significantly enhanced wakefulness in orexin/ataxin-3 narcoleptic mice (Shiba et al 2004). Next step will be the trial of H3-receptors in human narcoleptics.

\section{Endocrine therapy}

Thyrotrophin-releasing hormone (TRH) (Nishino et al 1997) and TRH agonists (Riehl et al 2000) have alerting properties. Moreover TRH has been shown to increase wakefulness and decrease cataplexy in canine narcolepsy (Nishino et al 1997). Whether these promising results in animal models will also extend to humans remains to be established.

\section{Hypocretin-based therapies}

There is no doubt that hypocretin/orexin deficiency is the cause of most narcolepsy in humans (Peyron et al 2000; Thannickal et al 2000). Thus the best standard for narcolepsy treatment is likely to aim at replacing the missing neurotransmitter. Various approaches may be considered:

1. Administration of hypocretin-1 (more stable than hypocretin-2) in both the blood and CSF. However, the blood-brain barrier is quite impermeable to hypocretin-1. Intranasal administration holds promise as hypocretin can get into the brain when administered through the nasal route (Hanson et al 2004). Experiments in humans are needed.

2. Cell transplantation. It was recently demonstrated that hypocretin neurons suspension cells, derived from posterior hypothalamus of 8- to 10-day-old rat pups, can survive when transplanted into the pons (a region of the brain that is innervated by hypocretin axons but where the hypocretin somata are not present) in adult rats (AriasCarrion et al 2004, 2006). These studies highlight the potential use of transplants as a therapeutic tool in order to treat narcolepsy. However, there are several issues at stake: low survival rate of transplanted cells, limited availability of donor cells, and immune reaction to the graft in view of the autoimmune hypothesis of narcolepsy. One possibility could be genetic engineering of cells delivering hypocretins, either using stem cell technology or genetically modified transplanted cells.

3. Gene therapy. Viral delivery of a transgene allowing the expression of hypocretin without proper anatomical distribution has been shown to be effective in mice (Miedaa et al 2004). However, an appropriate vector is needed.

\section{Immunotherapy}

Narcolepsy is a presumed autoimmune disorder (Silber et al 2007) and attempts to modify the immune process have been undertaken. Intil now steroids have been ineffective (Hecht et al 2003), while intravenous immunoglobulins (Lecendreux et al 2003; Dauvilliers et al 2004; Zuberi et al 2004; Fronczek et al 2008) as well as plasmaphoresis (Chen et al 2005) have given equivocal results.

\section{Manipulation of skin temperature and nocturnal sleep}

Skin-temperature regulation is altered in narcolepsy patients (Fronczek et al 2006). Interestingly proximal skin warning and distal skin cooling have been shown to lead to an increase in slow wave sleep and REM sleep and a decrease of wakefulness (Fronczek et al 2007), raising the possibility that temperature manipulation could supplement other established methods to improve nocturnal sleep in narcolepsy patients.

\section{Conclusion}

The current therapies of narcolepsy with cataplexy have been reviewed, as well as the present state of research on future therapeutic approaches.

On the former, several issues deserve consideration. Noradrenaline reuptake inhibitors and noradrenaline and serotonin reuptake inhibitors are extensively used in the treatment of cataplexy, but they totally lack randomized, double-blind, placebo-controlled studies for this indication, and their approval by major pharmacological agencies is not on the program. Due to its efficacy on the three groups of symptoms of narcolepsy, sodium oxybate is a fascinating alternative to the conventional treatment of narcolepsy with cataplexy. However, its position versus modafinil and new antidepressants is not yet settled.

As for future therapeutic approaches, the most challenging ones are hypocretin-based therapies. However, it is still too early to predict which of them will be available in the coming years.

\section{Disclosures}

The author has served on a Xyrem International Advisory Board (UCB Group).

\section{References}

Akimoto H, Honda Y, Takahashi Y. 1960. Pharmacotherapy in narcolepsy. Dis Nerv Syst, 21:1-3.

American Academy of Sleep Medicine. 2005. International classification of sleep disorders, 2nd ed.:Diagnostic and coding manual. Westchester, Illinois: American Academy of Sleep Medicine. 
Arias-Carrion O, Murillo-Rodriguez E, Xu M, et al. 2004. Transplantation of hypocretin neurons into the pontine reticular formation:preliminary results. Sleep, 27:1465-70.

Arias-Carrion O, Drucker-Colin R, Murillo-Rodriguez E. 2006. Survival rates through time of hypocretin grafted neurons within their projection site. Neurosci lett, 404:93-7.

Beer B, Stark J, Krieter P, et al. 2004. DOV 216,303, a 'triple' reuptake inhibitor: safety, tolerability, and pharmacokinetic profile. J Clin Pharmacol, 44:1360-7.

Beuersterien KM, Rogers AAE, Walsleben JA, et al. 1999. Health-related quality of life effects of modafinil for treatment of narcolepsy. Sleep, 22:757-65.

Billiard M, Bassetti C, Dauvilliers Y, et al. 2006. EFNS guidelines on management of narcolepsy. Eur J Neurol, 13:1035-48.

Billiard M, Besset A, Montplaisir J, et al. 1994. Modafinil: a double-blind multicenter study. Sleep, 17(Suppl):107-12.

Billiard M, Nicolet A, Dauvilliers Y, et al. 2007. Modafinil: the European experience. In Bassetti C, Billiard M, Mignot E. (eds) Narcolepsy and hypersomnia. New York. Informa Healthcare, pp. 561-9.

Black J, Houghton WC. 2006. Sodium oxybate improves excessive daytime sleepiness in narcolepsy. Sleep, 2:939-46.

Boeve BF, Silber MH, Ferman TJ. 2003. Melatonin for treatment of REM sleep behavior disorder in neurological disorders:results in 14 patients. Sleep Med, 4:281-4.

Britton T, Hansen A, Hicks J, et al. 2002. Guidelines on the diagnosis and management of narcolepsy in adults and children. Evidence-based guidelines for the UK with graded recommendations. Ashtead, UK: Taylor Patten Communications Ltd.

Broughton R, Ghanem Q, Hishikawa Y, et al. 1981. Life effects of narcolepsy in 180 patients from North-America, Asia and Europe compared to matched controls. Can J Neurol Sci, 8:299-304.

Broughton RJ, Fleming JAE, George CFP, et al. 1997. Randomized, doubleblind placebo-controlled crossover trial of modafinil in the treatment of excessive daytime sleepiness in narcolepsy. Neurology, 49:444-51.

Broughton R, Mamelak M. 1979. The treatment of narcolepsy-cataplexy with nocturnal gamma-hydroxybutyrate. Can J Neurol Sci, 6:1-6.

Broughton RJ, Murray BJ. 2007. The behavioral management of narcolepsy. In Bassetti C, Billiard M, Mignot E. (eds) Narcolepsy and hypersomnia New York. Informa Healthcare, p 497-512.

Chemelli RM, Willie JT, Sinton CM, et al. 1999. Narcolepsy in orexin knockout mice:molecular genetics of sleep regulation. Cell, 98:437-51.

Chen W, Black J, Einen M, et al. 2005. Late onset narcolepsy presenting as rapidly progressing muscle weaknes:response to plasmaphoresis. Ann Neurol, 58:489-90.

Chokroverty S. 1986. Sleep apnea in narcolepsy. Sleep, 9:250-3.

Dauvilliers Y, Carlander B, Touchon J, et al. 2004. Successful management of cataplexy with intravenous immunoglobulins at narcolepsy onset. Ann Neurol, 56:905-8.

Dauvilliers Y, Montplaisir J, Molinari N, et al. 2001. Age at onset of narcolepsy in two large populations of patients in France and Quebec. Neurology, 57:2029-33.

Fronczek R, Overeem S, Lammers GJ, et al. 2006. Altered skin-temperature regulation in narcolepsy relates to sleep propensity. Sleep, 29:1444-49.

Fronczek R, Raymann RJEM, Romeijn N, et al. 2008. Manipulation of core body and skin temperature improves vigilance and maintenance of wakefulness in narcolepsy. Sleep, 31:233-40.

Fronczek R, Verschuuren J, Lammers GJ. 2007. Response to intravenous immnoglobulin and placebo in a patient with narcolepsy with cataplexy. J Neurol, 254:1607-8.

Guilleminault C. 1993. Amphetamines and narcolepsy:use of the Stanford database. Sleep, 16:199-201.

Guilleminault C, Mancuso J, Quera-Salva MA, et al. 1986. Viloxazine hydrochloride in narcolepsy:a preliminary report. Sleep, 9:275-79.

Hanson LR, Martinez PM, Taheri S, et al. 2004. Intranasal administration of hypocretin-1 (orexin A) bypasses the blood-brain barrier and targets the brain:a new strategy for the treatment of narcolepsy. Drug Delivery Technol, 4:66-71.
Harsh JR, Hayduk R, Rosenberg R, et al. 2006. The efficacy and safety of armodafinil as treatment for adults with excessive sleepiness associated with narcolepsy. Curr Med Res Opin, 22:761-74.

Hecht M, Lin L, Kushida CA, et al. 2003. Report of a case of immunosuppression with prednisone in an 8-year-old boy with an acute onset of hypocretin-deficiency narcolepsy. Sleep, 26:809-10.

Hublin C, Kaprio J, Partinen M, et al. 1994a. The prevalence of narcolepsy: an epidemiological study of the Finnish Twin Cohort. Ann Neurol, 35:709-16.

Hublin C, Partinen M, Heinonen E, et al. 1994b. Selegiline in the treatment of narcolepsy. Neurology, 44:2095-101.

Iijima S, Sugita Y, Tshima Y, et al. 1986.Therapeutic effects of mazindol on narcolepsy. Sleep, 9:265-8.

Ivanenko A, Tauman R, Gauzal D. 2003. Modafinil in the treatment of excessive daytime sleepiness in children. Sleep Med, 4:579-82.

Kales A, Vela-Bueno A, Kales JD. 1987. Sleep disorders:sleep apnea and narcolepsy. Ann Intern Med, 106:434-43.

Keam S, Walker MC. 2007. Therapies for narcolepsy with or without cataplexy:evidence based review. Curr Opin Neurol, 20:699-703.

Kent JM. 2000. SnaRIs, NaSSAs, and NARIs:new agents for the treatment of depression. Lancet, 355:911-18. Erratum in: Lancet, $355: 2000$.

Langdon N, Shindler J, Parkes JD, et al. Fluoxetine in the treatment of cataplexy. Sleep, 9:371-3.

Larrosa O, de la Llave Y, Bario S, et al. 2001. Stimulant and anticataplectic effects of reboxetine in patients with narcolepsy. Sleep, 24:282-5.

Lecendreux M, Maret S, Bassetti C, et al. 2003. Clinical efficacy of highdose intravenous immunoglobulins near the onset of narcolepsy in a 10-year-old boy. J Sleep Res, 12:347-8.

Lin L, Faraco J, Li R, et al. 1999. The sleep disorder canine narcolepsy is caused by a mutation in the hypocretin (orexin) receptor 2 gene. Cell, 98:365-76.

Lin JS. 2000. Brain structures and mechanisms involved in the control of cortical activation and wakefulness, with emphasis on the posterior hypothalamus and histaminergic neurons. Sleep Med Rev, 4:471-503.

Lin JS, Sakai K, Vanni-Mercier G et al. 1990, Involvement of histaminergic neurons in arousal mechanisms demonstrated with $\mathrm{H} 3$-receptor ligands in the cat. Brain Res, 523:325-30.

Maitre M. 1997. The gamma-hydroxybutyrate signalling system in brain organisation and functional implications. Prog Neurobiol, 51:337-61.

Marelli S, Fantini M, Busek P, et al. 2006. Association between REM sleep behavior disorder and narcolepsy with and without cataplexy. Sleep, 29(Abstract Suppl):A229-30.

Martinez-Rodriguez J, Iranzo A, Santamaria J, et al. 2002. Status cataplecticus induced by abrupt withdrawal of clomipramine. Neurologia, 17:113-6.

Mayer G, Meier-Ewert K. 1995. Selegiline hydrochloride treatment in narcolepsy. A double-blind, placebo-controlled study. Clin Neuropharmacol, 18:306-19.

Mayer G, Peter H, Kesper K, et al. 2002. Komorbidität bei Narkolepsiepatienten. Dtsch Med Wochenschr, 127:1942-46.

Merrit SL, Cohen FL, Smith KM. 1992. Depressive symptomatology in narcolepsy. In Goswami M, et al. (eds). Psychosocial Aspects of Narcolepsy. New York: The Haworth Press, p 53-9.

Mieda M, Willie JT, Hara J, et al. 2004. Orexin peptides prevent cataplexy and improve wakefulness in an orexin-neuron-ablated model of narcolepsy in mice. Proc Natl Acad Sci USA, 101:4649-54.

Mignot E, Nishino S, Guilleminault C, et al. 1994. Modafinil binds to the dopamine uptake carrier site with low affinity. Sleep, 17:436-7.

Mitler MM, Aldrich MS, Koob GF, et al. 1994. Narcolepsy and its treatment with stimulants (ASDA standards of practice). Sleep, 17:352-71.

Mitler MM, Shafor R, Hajdukovik R, et al. 1986. Treatment of narcolepsy: objective studies on methylphenidate, pemoline, and protriptyline. Sleep, 9:260-4. 
Moldofsky H, Broughton RJ, Hill JD. 2000. A randomized trial of the long-term, continued efficacy and safety of modafinil in narcolepsy. Sleep Med, 1:109-16.

Montplaisir J, Michaud M, Denesle R, et al. 2000. Periodic leg movements are not more prevalent in insomnia or hypersomnia but are specifically associated with sleep disorders involving a dopaminergic impairment. Sleep Med, 1:163-7.

Morgenthaler TI, Kapur VK, Brown T, et al. 2007. Practice parameters for the treatment of narcolepsy and other hypersomnias of central origin. Sleep, 30:1705-11.

Murali H, Kotagal S. 2006. Off-label treatment of severe childhood narcolepsy-cataplexy with sodium oxybate. Sleep, 29:1025-9.

Niederhofer H. 2005. Atomoxetine also effective in patients suffering from narcolepsy? Sleep, 28:1189.

Nightingale S, Orgill JC, Ebrahim IO, et al. 2005. The association between narcolepsy and REM behavior disorder (RBD). Sleep Med, 6:253-8.

Nishino S, Arrigoni J, Shelton J, et al. 1997. Effects of thyrotropin-releasing hormone and its analogs on daytime sleepiness and cataplexy in canine narcolepsy. J Neurosci, 17:6401-8.

Nishino S, Kanbayashi T. 2005. Symptomatic narcolepsy, cataplexy and hypersomnia, and their implications in the hypothalamic hypocretin/ orexin system. Sleep Med Rev, 9:269-310.

Nishino S, Mao J, Sampathkumaran R, et al. 1998. Increased dopaminergic transmission mediates the wake-promoting effects of CNS stimulants. Sleep Res Online, 1:49-61.

Nishino S, Mignot E. 1997. Pharmacological aspects of human and canine narcolepsy. Progr Neurobiol, 52:27-78.

Ohayon MM, Priest RG, Zulley J, et al. 2002. Prevalence of narcolepsy symptomatology and diagnosis in the European general population. Neurology, 58:1826-33.

Pardi D, Black J. 2006. GHB/sodium oxybate:neurobiology and impact on sleep and wakefulness. CNS Drugs, 20:993-1018.

Parkes JD, Dahlitz M. 1993. Amphetamine prescription. Sleep, 16:201-3.

Peyron C, Faraco J, Rogers W, et al. 2000. A mutation in a case of early onset narcolepsy and a generalized absence of hypocretin peptides in human narcoleptic brains. Nat Med, 6:991-7.

Plazzi G, Montagna P, Provini F, et al. 2007. Treatment of narcolepsy with cataplexy. Lancet, 369:1081.

Prinzmetal M, Bloomberg W. 1935. The use of benzedrine for treatment of narcolepsy. JAMA, 105:2051-4.

Riehl J, Honda K, Kwan M, et al. 2000. Chronic oral administration of CG-3703, a thyrotropin-releasing hormone analog, increase wake and decreases cataplexy in canine narcolepsy. Neuropsychopharmacology, 23:34-45.

Rogers AE, Aldrich MS, Lin X. 2001. Comparison of three different sleep schedules for reducing daytime sleepiness in narcolepsy. Sleep, 24:385-91.

Roselaar SE, Langdon N, Lock CB, et al. 1987. Selegiline in the treatment of narcolepsy. Sleep, 10:491-5.

Schachter M, Parkes JD. 1980. Fluvoxamine and clomipramine in the treatment of cataplexy. J Neurol Neurosurg Psychiatr, 43:171-4.

Schenck CH, Mahowald MW. 1992. Motor dyscontrol in narcolepsy: rapid-eye-movement (REM) sleep without atonia and REM sleep behavior disorder. Ann Neurol, 32:3-10.

Schwartz JR, Nelson MT, Schwartz ER, et al. 2004. Effects of modafinil on wakefulness and executive function in patients with narcolepsy experiencing late-day sleepiness. Clin Neuropharmacol, 27:74-9.

Shiba T, Fujiki N, Wisor J, et al. 2004. Wake promoting effects of thioperamide, a histamine $\mathrm{H} 3$ antagonist in orexin/ataxin-3 narcoleptic mice. Sleep, 27(Abstract Suppl):A241-2.
Shindler J, Schachter M, Brincat S, et al. 1985. Amphetamines, mazindol and fencamfamin in narcolepsy. BMJ, 290:1167-70.

Silber MH, Black JL, Krahn LE, et al. 2007. Autoimmune studies in narcolepsy. In Bassetti C, Billiard M, Mignot E. (eds) Narcolepsy and hypersomnia. New York: Informa Healthcare. p 451-7.

Silber MH, Krahn LE, Olson EJ, et al. 2002. The epidemiology of narcolepsy in Olmsted county, Minnesota:a population-based study. Sleep, 25:197-202.

Smith M, Parkes JD, Dahlitz M. 1996. Venlafaxine in the treatment of the narcoleptic syndrome. J Sleep Res, 5(Suppl 1):217.

Standards of Practice Committee. 2001. Practice parameters for the treatment of narcolepsy:an update for 2000. Sleep, 24:451-66.

Standards of Practice Committee of the American Sleep Disorders Association. 1994. Practice parameters for the use of stimulants in the treatment of narcolepsy. Sleep, 17:348-51.

Tatsumi M, Groshan K, Blakely RD, et al. 1997. Pharmacological profile of antidepressants and related compounds at human monoamine transporters. Eur J Pharmacol, 340:249-58.

Tedford CE, Edgar DM, Seidel WF, et al. 1999. Effects of a novel, selective and potent histamine $\mathrm{H} 3$ receptor antagonist, GT-2332, on rat sleep/ wakefulness and canine cataplexy. Abstr Soc Neurosci, 25:1134.

Thannickal TC, Moore RY, Nienhuis R, et al. 2000. Reduced number of hypocretin neurons in human narcolepsy. Neuron, 27:469-74.

The Xyrem ${ }^{\circledR}$ International Study Group. 2005. A double-blind, placebocontrolled study demonstrates that sodium oxybate is effective for the treatment of excessive daytime sleepiness in narcolepsy. J Clin Sleep Med, 1:391-7.

Thorpy MJ, Black J, Erman MK. 2004. The safety profile of modafinil in disorders of sleep and wakefulness. Neurology, 62(Suppl 5): A56-7.

Thorpy MJ, Snyder M, Aloes FS, et al. Short-term triazolam use improves nocturnal sleep of narcolepstics. Sleep, 1992:15:212-6.

US Modafinil in Narcolepsy Multicenter Study Group. 1998. Randomized trial of modafinil for the treatment of pathological somnolence in narcolepsy. Ann Neurol, 43:88-97.

US Modafinil in Narcolepsy Multicenter Study Group. 2000. Randomized trial of modafinil as a treatment for the excessive daytime somnolence of narcolepsy. Neurology, 54:1166-75.

US Xyrem ${ }^{\circledR}$ Multicenter Study Group. 2002. A randomized, double blind, placebo-controlled multicenter trial comparing the effects of three doses of orally administered sodium oxybate with placebo for the treatment of narcolepsy. Sleep, 25:42-9.

US Xyrem ${ }^{\circledR}$ Multicenter Study Group. 2003. A 12-month, open-label, multicenter extension trial of orally administered sodium oxybate for the treatment of narcolepsy. Sleep, 26:31-5.

US Xyrem ${ }^{\circledR}$ Multicenter Study Group. 2004. Sodium oxybate demonstrates long-term efficacy for the treatment of cataplexy in patients with narcolepsy. Sleep Med, 5:119-23.

Xyrem ${ }^{\circledR}$ International Study Group. 2005. Further evidence supporting the use of sodium oxybate for the treatment of cataplexy:a double-blind, placebo-controlled study in 228 patients. Sleep Med, 6:415-21.

Wing YK, Li RH, Lam CW, et al. 2002. The prevalence of narcolepsy among Chinese in Hong-Kong. Ann Neurol, 51:578-84.

Wisor JP, Nishino S, Sora I, et al. 2001. Dopaminergic role in stimulant induced wakefulness. $J$ Neurosci, 21:1787-94.

Wyatt RJ, Fram DH, Buchbinder R, et al. 1971. Treatment of intractable narcolepsy with a monoamine oxidase inhibitor. $N$ Engl $J$ Med, 285:987-91

Zuberi SM, Mignot E, Ling L, et al. 2004. Variable response to intravenous immunoglobulin therapy in childhood narcolepsy. J Sleep Res, 13(Suppl 1):828. 